\title{
Autonomic modulation of heart rate of young and postmenopausal women undergoing estrogen therapy
}

V.F.C. Neves ${ }^{1}$, M.F. Silva de Sá2, L. Gallo Jr. ${ }^{3}$, A.M. Catai ${ }^{1}$, L.E.B. Martins ${ }^{4}$, J.C. Crescêncio ${ }^{3}$, N.M. Perpétuo ${ }^{5}$ and E. Silva ${ }^{1,5}$

\section{Correspondence}

V.F.C. Neves

Núcleo de Pesquisa em Exercício

Físico

Laboratório de Fisioterapia

Cardiovascular

Departamento de Fisioterapia, UFSCar

Rodovia Washington Luís, km 235

13565-905 São Carlos, SP

Brasil

Fax: +55-16-3361-2081

E-mail: valeria0208@ig.com.br.

Some of the results were presented at the III Congresso de Pós-Graduação/6a Jornada Científica da UFSCar, São Carlos, SP, Brazil, October 10-14, 2005.

Research supported by CNPq (No. 140684/2003-4) and FAPESP (No. 01/07427-2).

Received March 29, 2006 Accepted December 18, 2006

\author{
${ }^{1}$ Núcleo de Pesquisa em Exercício Físico, Laboratório de Fisioterapia Cardiovascular, \\ Departamento de Fisioterapia, Universidade Federal de São Carlos, São Carlos, SP, \\ Brasil \\ ${ }^{2}$ Departamento de Ginecologia e Obstetrícia, ${ }^{3}$ Divisão de Cardiologia, \\ Departamento de Clínica Médica, Hospital das Clínicas, \\ Faculdade de Medicina de Ribeirão Preto, Universidade de São Paulo, \\ Ribeirão Preto, SP, Brasil \\ ${ }^{4}$ Laboratório de Fisiologia do Exercício, Faculdade de Educação Física, \\ Universidade Estadual de Campinas, Campinas, SP, Brasil \\ ${ }^{5}$ Laboratório de Pesquisa em Fisioterapia Cardiovascular e de Provas Funcionais, \\ Faculdade de Ciências da Saúde, Universidade Metodista de Piracicaba, \\ Piracicaba, SP, Brasil
}

\section{Abstract}

The aim of the present study was to determine whether estrogen therapy (ET) reduces alterations of the autonomic control of heart rate (HR) due to hypoestrogenism and aging. Thirteen young $(24 \pm 2.6$ years), 10 postmenopausal ( $53 \pm 4.6$ years) undergoing ET (PM-ET), and 14 postmenopausal $(56 \pm 2.6$ years $)$ women not undergoing ET (PM) were studied. ET consisted of $0.625 \mathrm{mg} /$ day conjugated equine estrogen. HR was recorded continuously for $8 \mathrm{~min}$ at rest in the supine and sitting positions. HR variability (HRV) was analyzed by time (SDNN and rMSSD indices) and frequency domain methods. Power spectral components are reported as normalized units (nu) at low (LF) and high (HF) frequencies, and as LF/HF ratio. Intergroup comparisons: SDNN index was higher in young (median: supine, $47 \mathrm{~ms}$; sitting, $42 \mathrm{~ms})$ than in PM-ET (33; $29 \mathrm{~ms})$ and PM (31; $29 \mathrm{~ms})$ women $(\mathrm{P}<0.05)$. PM showed lower HFnu, higher LFnu and higher LF/HF ratio (supine: $44,56,1.29$; sitting: $38,62,1.60$ ) than the young group in the supine position $(61,39,0.63)$ and the PM-ET group in the sitting position $(57,43,0.75 ; \mathrm{P}<0.05)$. Intragroup comparisons: HR was lower in the supine than in the sitting position for all groups $(\mathrm{P}<0.05)$. The HRV decrease from the supine to the sitting position was significant only in the young group. These results suggest that HRV decreases during aging. ET seems to attenuate this process, promoting a reduction in sympathetic activity on the heart and contributing to the cardioprotective effect of estrogen hormones.
Key words

- Heart rate variability

- Aging

- Menopause

- Estrogen therapy 


\section{Introduction}

Epidemiological studies have demonstrated that, after menopause, women present an increased incidence of cardiovascular disease (1). It is believed that this higher vulnerability is related to the occurrence of decreased estrogen levels during this period (2). During the last decade, the positive effect of hormone therapy on the incidence of coronary artery diseases (CAD) as well as on the morbidity and mortality of cardiovascular disease has been demonstrated $(3,4)$. The mechanisms involved in the prophylactic action of estrogens may be mainly related to the promotion of an antiatherogenic lipid profile and the action on blood vessel walls $(5,6)$. More recently, however, two large scale randomized clinical studies on postmenopausal women with (7) or without (8) CAD indicated that hormone therapy may not be beneficial and may actually increase the risk of cardiovascular events (8).

The study of heart rate variability (HRV) is an important tool for a noninvasive evaluation of the integrity of neurocardiac function (9). It has been proposed that a decrease in HRV is a powerful predictor of morbidity and mortality consequent to arrhythmic complications (10).

Autonomic modifications of cardiovascular control have also been observed in the aging process $(11,12)$. In women, both aging and postmenopausal hormonal changes contribute to modifications of the autonomic control of the heart. Brockbank et al. (13) and Liu et al. (14) noted higher HRV values in premenopausal than in postmenopausal women. Mercuro et al. (15) observed decreased HRV indices in women submitted to bilateral oophorectomy. However, when these patients were placed on therapy with 17ß-estradiol, all HRV indices returned to their pre-surgery levels. Others (14,16-18) have investigated whether hormone therapy could influence the action of the autonomic nervous system on the heart. Yet, the prob- lem remains without a definitive solution. The objective of the present study was to test the hypothesis that the use of estrogen therapy could attenuate changes in the autonomic control of heart rate (HR) due to the hypoestrogenism that accompanies the aging process since a decrease in HRV has been associated with increased risks for cardiac events (10).

\section{Material and Methods}

A cross-sectional study was conducted on 37 healthy young and postmenopausal women who fulfilled established criteria. The young subjects presented regular menstrual cycles and were not using anticonceptional drugs. Experimental procedures were always performed during the follicular phase of their cycle, when hormonal variations are not influenced by progesterone. The postmenopausal state was defined as age above 48 years, the absence of a menstrual cycle for the last 12 months for patients who had uterus and serum follicular-stimulating hormone levels above $30 \mathrm{mIU} / \mathrm{mL}$. None of the subjects followed any program of regular aerobic exercise. Subjects showing evidence of cardiac or respiratory disease, hypertension (blood pressure $\geq 140 / 90 \mathrm{mmHg}$ ), diabetes mellitus, thromboembolic disease, dysthyroidism, stroke, depression, obesity (body mass index $\geq 30 \mathrm{~kg} / \mathrm{m}^{2}$ ), or a history of smoking or alcoholism were excluded from the study. None of the subjects were using sedatives, anti-hypertensive or anti-arrhythmic medication, or other medications able to affect autonomic control of HR.

Thirteen young women, 14 postmenopausal women not undergoing hormone therapy and 10 women undergoing estrogen therapy for at least one year took part in the study. In the last group, all women had a previous history of hysterectomy and were continuously using oral conjugated equine estrogen at doses of $0.625 \mathrm{mg} / \mathrm{day}$. This hormonal treatment had been indicated to 
subjects showing vasomotor symptoms, osteopenia or osteoporosis. Age and anthropometric and clinical characteristics of the subjects in the groups studied are presented in Table 1.

Blood pressure was measured to confirm that it was within normal limits. Two measurements were performed on two non-consecutive days by the brachial artery auscultatory method using a mercury column sphygmomanometer (WanMed, São Paulo, SP, Brazil) and a stethoscope (Littmann, St. Paul, MN, USA). For this procedure the subjects remained at rest in the sitting position for at least $5 \mathrm{~min}$, with feet on the floor, and the arm supported at heart level (19). The mean blood pressure values are reported in Table 1.

All subjects included in the present study had blood count, urinalysis and electrocardiogram at rest within normal limits. The results of the maximum treadmill exercise test were negative for myocardial ischemia and arrhythmia in all cases. Additionally, the results of clinical biochemical screening tests (glucose, total cholesterol and fractions, triglycerides, urea, creatinine, thyroidstimulating hormone, and serum estradiol) are presented in Table 2.

The subjects were also submitted to a continuous dynamic exercise test up to physical exhaustion on a cycle ergometer (model Corival 400, Quinton, Seattle, WA, USA) with 10 to $20 \mathrm{~W} / \mathrm{min}$ increments. During the test, ventilatory and metabolic measurements were obtained on a breath-by-breath basis using a specific metabolic analyzer (CPXD, Medical Graphics, St. Paul, MN, USA). Aerobic capacity was then evaluated using oxygen uptake $\left(\mathrm{V}_{2}\right)$ data obtained at the peak of exercise.

The study was approved by the Ethics Committee of the University Hospital, Faculty of Medicine of Ribeirão Preto, University of São Paulo, and by the Ethics Committee of the Federal University of São Carlos, São Carlos, SP, Brazil. The purpose of the study was explained to each subject prior to obtaining written informed consent.

\section{Measurement of heart rate variability}

Experiments were always carried out in the morning in order to avoid response differences due to circadian changes. Room temperature was kept at $22^{\circ} \mathrm{C}$ and relative air humidity between 40 and $60 \%$. Subjects were acquainted with the experimental protocol and instructed to abstain from stimulants and alcoholic beverages during the 24 $\mathrm{h}$ preceding the exam, and to ingest a light meal at least $2 \mathrm{~h}$ prior to the measurement.

On each experimental day, the subjects were interviewed and examined prior to the beginning of the test to verify their continued good health and if they had had a normal night's sleep. After a 15-min rest in the supine position, blood pressure and HR were measured to determine whether the basal conditions of the subjects were adequate for the experiment.

An electrocardiogram and HR data were obtained from a one-channel heart monitor (TC500, ECAFIX, São Paulo, SP, Brazil) and processed using an analog-to-digital converter Lab. PC+ (National Instruments Co., Austin, TX, USA), which represented the interface between the heart monitor and a Pentium III microcomputer. Signals were recorded in real time after analog-to-digital conversion at a sampling rate of $500 \mathrm{~Hz}$, and the R-R intervals (ms) were calculated on a beat-to-beat basis using specific software (20). To evaluate the effect of body position on the HR response and its variability, R-R intervals were recorded over an 8-min period under resting conditions with the subjects in the supine and sitting positions, respectively, and breathing spontaneously.

HRV was assessed in both time and frequency domains. The region of greatest stability for the gathering of the R-R intervals was used for this measurement, so that at least 256 consecutive beats (9) were pre- 
sented. The selected time domain parameters studied were the mean of the R-R intervals, the standard deviation of the R-R intervals (SDNN) and the square root of the mean of the sum of the squares of differences between adjacent R-R intervals (rMSSD). SDNN reflected overall HRV, whereas rMSSD was considered to be an index of parasympathetic modulations of HR (9).

For the frequency domain, spectral analysis was performed by fast Fourier transformation applied to a single window after a linear trend subtraction, at the R-R intervals previously chosen. The power spectral components were obtained at low (LF: 0.04 to
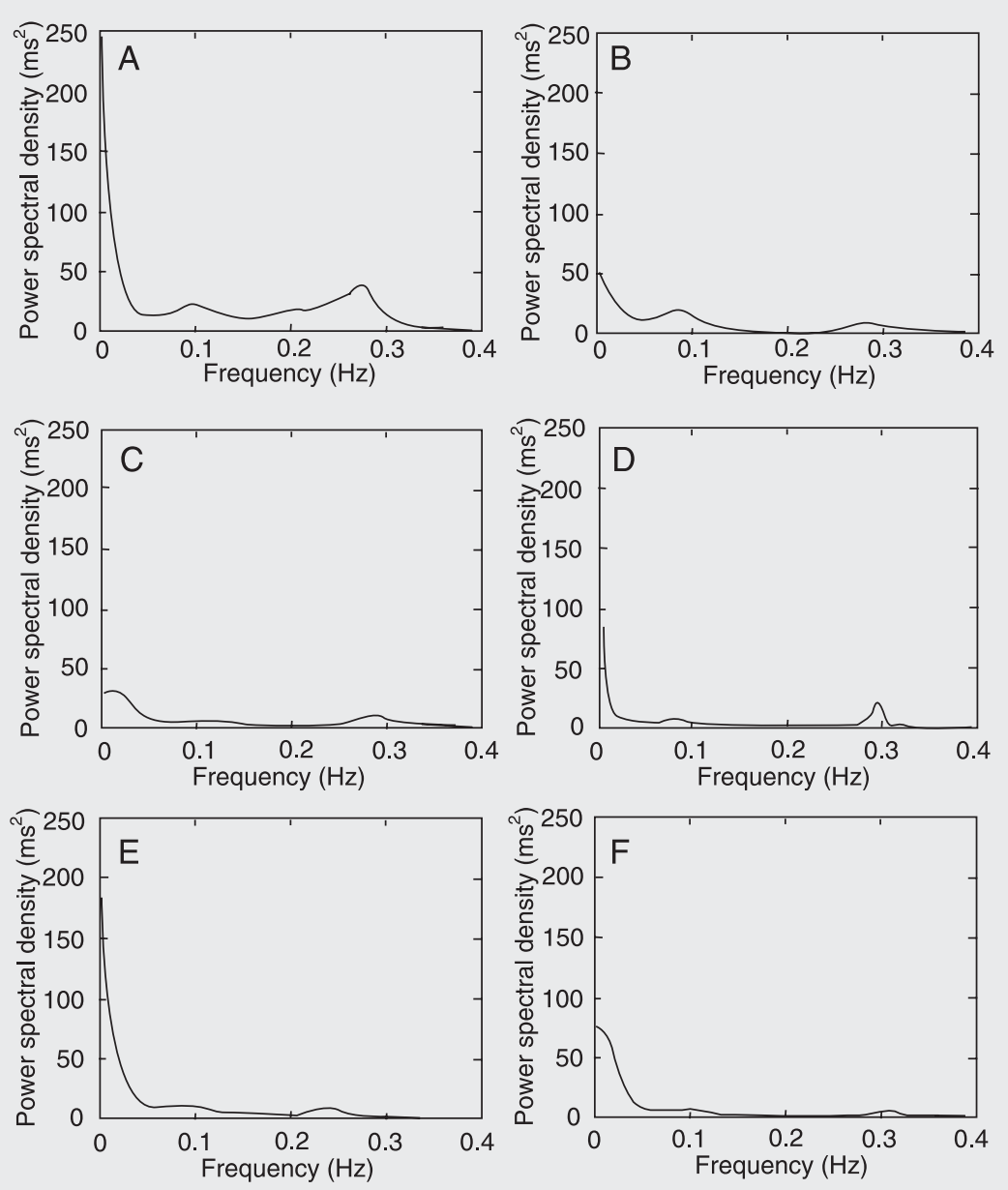

Figure 1. Heart rate variability power spectra of a representative subject from the groups of young women $(A$ and $B)$, postmenopausal women undergoing $(C$ and $D)$ and not undergoing ( $E$ and $F$ ) estrogen therapy obtained at rest in the supine and sitting positions, respectively. Spectral components are shown as low frequency $(0.04$ to $0.15 \mathrm{~Hz})$, high frequency (0.15 to $0.4 \mathrm{~Hz}$ ) and very low frequency (below $0.04 \mathrm{~Hz}$ ).
$0.15 \mathrm{~Hz}$ ) and high (HF: 0.15 to $0.4 \mathrm{~Hz}$ ) frequencies, in absolute units $\left(\mathrm{ms}^{2}\right)$, and the normalized units were computed by dividing the absolute power of a given LF or HF component $\left(\mathrm{ms}^{2}\right)$ by the total power minus very low frequency $(0.003-0.04 \mathrm{~Hz})$ power and then multiplying this ratio by 100 . Since the LF band is modulated by both the sympathetic and the parasympathetic nervous systems and the HF band is correlated with vagal cardiac control, the $\mathrm{LF} / \mathrm{HF}$ ratio was calculated to determine the sympatho-vagal balance (9). Figure 1, which was drawn using an autoregressive model, illustrates the HRV power spectra at rest in the supine and sitting positions of a representative subject from each group.

\section{Statistical analysis}

One-way ANOVA was performed to compare the physical and clinical characteristics of the three experimental groups and, when appropriate, post hoc analyses were conducted using the Tukey HSD for unequal $\mathrm{N}$. HRV indices obtained during the experimental trials were tested for normality. Since the data were shown not to be normally distributed, comparisons between groups were performed using the Kruskal-Wallis test and, when appropriate, post hoc analyses were conducted using Dunn's multiple comparison test. For intragroup analysis, the Wilcoxon matched-pair test was used. For association between variables, the Spearman correlation test was used. The level of significance was set at $\mathrm{P}<0.05$. Data are reported as medians followed by $95 \%$ confidence intervals. Figures 1 and 2 were drawn using MatLab software 6.1.0.450, release 12.1 .

\section{Results}

No significant differences in weight or height were observed between groups. The subjects of the younger group had lower 
body mass index, blood pressure and a higher $\dot{\mathrm{V}} \mathrm{O}_{2 \text { peak }}$, reported as absolute and normalized values for body weight, than the postmenopausal groups $(\mathrm{P}<0.05$; Table 1$)$. No significant differences in mean menopausal time periods were observed between the postmenopausal groups. The average period of estrogen therapy used was $6 \pm 4.6$ years.

Table 2 shows that there were no significant differences in serum concentrations of glucose, triglyceride, HDL cholesterol, urea, creatinine, or thyroid-stimulating hormone between groups. The young group presented significantly lower $(\mathrm{P}<0.05)$ total cholesterol values compared to the postmenopausal groups, and lower LDL cholesterol values compared to subjects not using estrogen. Serum follicular-stimulating hormone levels did not differ between the postmenopausal groups, but the serum estradiol levels were higher in the postmenopausal group undergoing estrogen therapy $(\mathrm{P}<0.05)$.

Intergroup comparisons showed that $\mathrm{HR}$ and R-R intervals at rest did not differ between the groups studied. However, analysis of the time domain demonstrated that the group of young subjects presented significantly $(\mathrm{P}<0.05)$ higher values for the SDNN index compared to those of the two postmenopausal groups. The rMSSD index of the younger group was higher than those of the postmenopausal groups, but the difference was only statistically significant $(\mathrm{P}<$ 0.05) in relation to the subjects not using estrogens (Table 3). Frequency domain analysis showed that the postmenopausal group not undergoing hormone therapy presented lower values of the HF normalized unit (HFnu) components $(\mathrm{P}<0.05)$, and higher LFnu components and LF/HF ratio $(\mathrm{P}<$ $0.05)$ relative to the young group, in the supine position (Table 3), and the postmenopausal group undergoing estrogen therapy, in the sitting position (Table 3 and Figure 2).

No significant correlation was observed between $\mathrm{HRV}$ and body mass index, $\mathrm{VO}_{2}$ peak, triglycerides, or total cholesterol and fractions. However, LFnu, HFnu and LF/HF ratio (sitting position) presented a significant correlation with serum estradiol levels $\left(\mathrm{r}_{\mathrm{s}}=-0.59,0.59\right.$, and -0.59 , respectively; $\mathrm{P}<$ $0.05)$.

In intragroup comparisons, lower HR values and higher values for the R-R intervals in the supine position were observed in relation to the sitting position in all three groups studied. These differences were sta-

Table 1. Age and anthropometric and clinical characteristics of the groups studied.

\begin{tabular}{|c|c|c|c|}
\hline Characteristics & $\begin{array}{l}\text { Young } \\
(N=13)\end{array}$ & $\begin{array}{l}\text { PM with ET } \\
(N=10)\end{array}$ & $\begin{array}{l}\text { PM without ET } \\
\qquad(N=14)\end{array}$ \\
\hline Age (years) & $24 \pm 2.6$ & $53 \pm 4.6^{*}$ & $56 \pm 2.6^{*}$ \\
\hline Weight (kg) & $57 \pm 6.0$ & $66 \pm 9.9$ & $62 \pm 9.4$ \\
\hline Height $(\mathrm{cm})$ & $163 \pm 6.0$ & $157 \pm 5.8$ & $158 \pm 6.1$ \\
\hline BMI $\left(\mathrm{kg} / \mathrm{m}^{2}\right)$ & $21.6 \pm 2.5$ & $26.6 \pm 4.0^{*}$ & $24.8 \pm 3.2^{*}$ \\
\hline $\mathrm{SBP}(\mathrm{mmHg})$ & $99 \pm 8.6$ & $114 \pm 11.7^{\star}$ & $118 \pm 17.6^{*}$ \\
\hline $\mathrm{DBP}(\mathrm{mmHg})$ & $67 \pm 5.5$ & $76 \pm 6.9^{\star}$ & $76 \pm 10.4^{\star}$ \\
\hline$\dot{\mathrm{V}} \mathrm{O}_{2 \text { peak }}(\mathrm{mL} / \mathrm{min})$ & $1287 \pm 148.5$ & $918 \pm 114.3^{*}$ & $929 \pm 150.6^{*}$ \\
\hline $\mathrm{VO}_{2 \text { peak }}\left(\mathrm{mL} \mathrm{kg}{ }^{-1} \mathrm{~min}^{-1}\right)$ & $22.6 \pm 3.1$ & $14.2 \pm 1.5^{*}$ & $14.8 \pm 2.7^{*}$ \\
\hline Menopause time (years) & - & $7 \pm 4.6$ & $8 \pm 4.8$ \\
\hline ET time (years) & - & $6 \pm 4.6$ & - \\
\hline
\end{tabular}

Data are reported as means $\pm \mathrm{SD}$. $\mathrm{PM}=$ postmenopausal; $\mathrm{ET}=$ estrogen therapy; $\mathrm{BMI}$ = body mass index; SBP = systolic blood pressure; $\mathrm{DBP}=$ diastolic blood pressure; $\dot{\mathrm{VO}}_{2}=$ oxygen uptake.

${ }^{*} \mathrm{P}<0.05$ compared to young women (one-way ANOVA and post hoc Tukey test).

Table 2. Clinical biochemical characteristics of the groups studied.

\begin{tabular}{lccc}
\hline & $\begin{array}{c}\text { Young } \\
(\mathrm{N}=13)\end{array}$ & $\begin{array}{c}\text { PM with ET } \\
(\mathrm{N}=10)\end{array}$ & $\begin{array}{c}\text { PM without ET } \\
(\mathrm{N}=14)\end{array}$ \\
\hline Glucose $(\mathrm{mg} / \mathrm{dL})$ & $80 \pm 6.2$ & $86 \pm 9.2$ & $88 \pm 11.2$ \\
Triglyceride $(\mathrm{mg} / \mathrm{dL})$ & $78 \pm 28.9$ & $141 \pm 70.1$ & $133 \pm 69.5$ \\
Total cholesterol $(\mathrm{mg} / 100 \mathrm{~mL})$ & $174 \pm 28.5$ & $221 \pm 51.0^{*}$ & $216 \pm 38.2^{*}$ \\
LDL cholesterol $(\mathrm{mg} / 100 \mathrm{~mL})$ & $102 \pm 28.3$ & $134 \pm 39.7$ & $140 \pm 35.6^{*}$ \\
HDL cholesterol $(\mathrm{mg} / 100 \mathrm{~mL})$ & $56 \pm 9.7$ & $59 \pm 10.4$ & $49 \pm 14.8$ \\
Urea $(\mathrm{mg} / \mathrm{dL})$ & $32 \pm 3.6$ & $28 \pm 4.6$ & $28 \pm 6.9$ \\
Creatinine $(\mathrm{mg} / \mathrm{dL})$ & $0.9 \pm 0.1$ & $0.9 \pm 0.1$ & $0.9 \pm 0.2$ \\
TSH $(\mathrm{mlU} / \mathrm{mL})$ & $2.0 \pm 0.7$ & $1.6 \pm 1.5$ & $2.5 \pm 2.0$ \\
FSH $(\mathrm{mlU} / \mathrm{mL})$ & - & $60 \pm 38.2$ & $75 \pm 45.2$ \\
Serum estradiol $(\mathrm{pg} / \mathrm{mL})$ & - & $58 \pm 25.4$ & $23 \pm 5.4^{\star *}$ \\
\hline
\end{tabular}

Data are reported as means \pm SD. $\mathrm{PM}=$ postmenopausal; $\mathrm{ET}=$ estrogen therapy; LDL = low-density lipoprotein; $\mathrm{HDL}=$ high-density lipoprotein; $\mathrm{TSH}=$ thyroid-stimulating hormone; FSH = follicular-stimulating hormone.

${ }^{*} \mathrm{P}<0.05$ compared to young women; ${ }^{* *} \mathrm{P}<0.05$ compared to $\mathrm{PM}$ women with $\mathrm{ET}$ (one-way ANOVA and post hoc Tukey test). 
tistically significant $(\mathrm{P}<0.05$; Table 3$)$. Concerning HRV, only the group of young subjects presented decreased $(\mathrm{P}<0.05)$ indices, reflecting vagal activity (rMSSD and HFnu) and an increase $(\mathrm{P}<0.05)$ in the indices reflecting sympathetic activity (LFnu and the LF/HF ratio) in the sitting position compared to the supine position. Figure 1 shows the differences in the distribution of spectral components for both body positions for a representative subject from each group. Particularly in the young group, a predominance of the HF and LF components was observed in the supine and sitting position, respectively.

\section{Discussion}

The effects of hormone therapy on HRV indices have been reported in heterogeneous and controversial forms, with some studies presenting favorable results $(14,17,21-23)$,

\begin{tabular}{|c|c|c|c|}
\hline Variable & $\begin{array}{l}\text { Young } \\
(N=13)\end{array}$ & $\begin{array}{l}\text { PM with ET } \\
(N=10)\end{array}$ & $\begin{array}{l}\text { PM without ET } \\
\quad(N=14)\end{array}$ \\
\hline \multicolumn{4}{|l|}{ Supine position } \\
\hline Heart rate $(\mathrm{bpm})$ & $70(65 ; 75)$ & $66(61 ; 72)$ & $66(64 ; 68)$ \\
\hline $\mathrm{R}-\mathrm{R}$ interval (ms) & $860(804 ; 916)$ & $904(831 ; 979)$ & $912(878 ; 947)$ \\
\hline SDNN (ms) & $47(40 ; 54)$ & $33(27 ; 39)^{\star}$ & $31(27 ; 36)^{*}$ \\
\hline rMSSD (ms) & $43(32 ; 54)$ & $28(20 ; 35)$ & $19(16 ; 22)^{*}$ \\
\hline LF (nu) & $39(32 ; 46)$ & $41(32 ; 50)$ & $56(51 ; 61)^{*}$ \\
\hline HF (nu) & $61(54 ; 68)$ & $59(50 ; 68)$ & $44(39 ; 49)^{*}$ \\
\hline LF/HF & $0.63(0.42 ; 0.84)$ & $0.70(0.41 ; 1.00)$ & $1.29(1.04 ; 1.54)^{\star}$ \\
\hline \multicolumn{4}{|l|}{ Sitting position } \\
\hline Heart rate $(\mathrm{bpm})$ & $74(68 ; 80)^{\star \star \star}$ & $72(65 ; 79)^{\star \star \star}$ & $69(65 ; 72)^{\star \star \star}$ \\
\hline $\mathrm{R}-\mathrm{R}$ interval (ms) & $808(748 ; 868)^{\star \star *}$ & $832(749 ; 915)^{\star \star *}$ & $872(823 ; 921)^{\star \star *}$ \\
\hline SDNN (ms) & $42(32 ; 52)$ & $29(26 ; 32)^{\star}$ & $29(26 ; 33)^{\star}$ \\
\hline rMSSD (ms) & $37(31 ; 43)^{\star \star \star}$ & $24(19 ; 29)$ & $17(14 ; 20)^{*}$ \\
\hline LF (nu) & $49(40 ; 58)^{\star \star *}$ & $43(35 ; 50)$ & $62(58 ; 66)^{\star \star}$ \\
\hline HF (nu) & $51(42 ; 60)^{\star \star \star}$ & $57(50 ; 65)$ & $38(34 ; 42)^{\star \star}$ \\
\hline $\mathrm{LF} / \mathrm{HF}$ & $0.96(0.57 ; 1.35)^{\star \star *}$ & $0.75(0.50 ; 0.99)$ & $1.60(1.29 ; 1.91)^{\star}$ \\
\hline
\end{tabular}

Data are reported as medians and $95 \%$ confidence intervals. $\mathrm{PM}=$ postmenopausal; $\mathrm{ET}$ = estrogen therapy; SDNN = standard deviation of the R-R intervals; rMSSD = square root of the mean of the sum of the squares of differences between adjacent $R$ $\mathrm{R}$ intervals; $\mathrm{LF}=$ low frequency; $\mathrm{HF}=$ high frequency; $\mathrm{nu}=$ normalized units; $\mathrm{LF} / \mathrm{HF}=$ low frequency/high frequency ratio.

${ }^{*} \mathrm{P}<0.05$ compared to young women; ${ }^{* *} \mathrm{P}<0.05$ compared to $\mathrm{PM}$ women with $\mathrm{ET}$; ${ }^{* *} \mathrm{P}$ $<0.05$ compared to the supine position (intergroup comparisons: Kruskal-Wallis and post hoc Dunn test; intragroup comparisons: Wilcoxon test). while others failed to find any modifications $(16,18)$. Christ et al. (24) observed a decreased HRV and considered this effect to be restricted to a subgroup that used estrogen plus progesterone.

The objective of the present investigation was to evaluate the relative influence of age, hypoestrogenism and estrogen therapy on the autonomic control of HR during rest in the supine and sitting positions.

Autonomic modulation of HR has been documented as progressively declining with aging. This process has been demonstrated both by the reduction of vagal activity indices and of indices that reflect sympathetic activity on the heart $(11,25)$. Since significantly decreased temporal indices of HRV were observed in postmenopausal women our results agree with the literature. Although the present study shows decreased aerobic capacity, increased body mass index and lipid profile modifications with aging, these variables did not present a significant correlation with HRV indices. Similar results were observed by Byrne et al. (26), suggesting that age is the major factor responsible for HRV reduction in the aging.

However, hypoestrogenism is another factor that could have influenced our results because the estrogen-treated group presented intermediate HRV values. Previous studies have also shown changes in the autonomic control of HR following natural (12-14,27) or surgical menopause (15). In agreement with the results of these studies, our results show that menopause can cause an imbalance of the autonomic nervous control of the cardiovascular system that shifts toward sympathetic hyperactivity. This could explain, in part, the increased incidence of cardiovascular diseases observed in postmenopausal women (1).

We also observed that postmenopausal women using estrogen therapy presented higher HFnu values and lower LFnu values, as well as lower LF/HF ratio compared to non-users of hormones. Considering our ex- 
perimental design, some factors could have influenced these results, such as age, anthropometric characteristics, clinical status, biochemical tests, and aerobic capacity. However, no significant differences were observed between the postmenopausal groups for any of the variables measured, except for the serum estradiol levels and the HRV indices described above, which showed a statistically significant correlation. These findings suggest that there is a significant relationship between several HRV indices and serum estradiol levels (estrogen therapy) in the postmenopausal women studied.

Therefore, the present findings agree with previous studies $(14,15,27)$, which have reported increased vagal activity and reduced sympathetic drive in postmenopausal women undergoing estrogen therapy. Nevertheless, the mechanism responsible for the beneficial effect of estrogen therapy on autonomic control of HR remains unknown and should be explored in future studies.

The divergence in the literature on the effects of hormone therapy on HRV may be due to the different types of hormones used, as well as to differences in dosage and route of administration. The patient's age at hormone utilization and prescription also appears to interfere with the results. Indeed, at this time, the results of the Heart and Estrogen/Progestin Replacement Study (7) and of the Women's Health Initiative (WHI) Study (8) regarding the increased risk of cardiovascular events have been questioned because the mean age of the patients was very high. Actually, the WHI data showed significant differences in the risk of CAD between groups corrected by age, and the results showed a lower risk of CAD in estrogen-treated patients at the age of 60 years or less (28). Therefore, hormonal therapy must begin at the appropriate time ("window of opportunity") when endothelial function is still normal. In the present study, the menopause period of the estrogen-treated group was still within the time span when hormone therapy has favorable effects on the cardiovascular system.

The postural change from the supine to
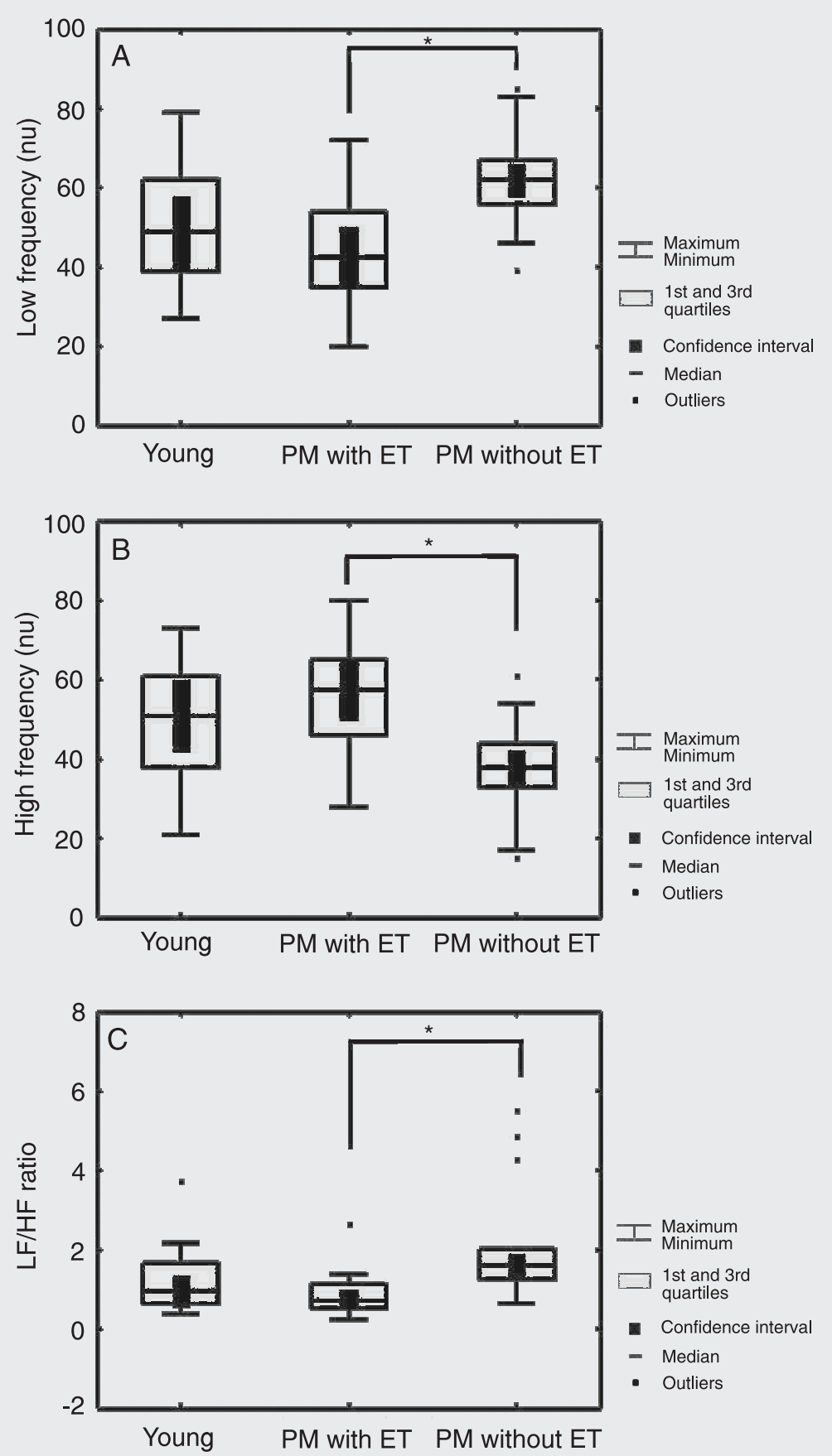

Figure 2. Low frequency normalized units (nu) (A), high frequency (nu) (B) and low frequency/high frequency (LF/HF) ratio $(C)$ in young and postmenopausal $(P M)$ women with or without estrogen therapy (ET), measured at rest in the sitting position. ${ }^{*} \mathrm{P}<0.05$ for the comparisons (Kruskal-Wallis and post hoc Dunn test). 
the sitting position provokes a reduction in venous return and a consequent HR elevation due to cardiac autonomic regulation (i.e., sympathetic activation and decreased vagal activity), which are mediated by arterial and cardiopulmonary baroreceptor adjustment (29). In the present study, all groups presented modifications in the chronotropic response as a function of body position. On the other hand, variation of sympatho-vagal modulation was only noted in the younger group. These results suggest that the baroreflex control of HR could be altered by the aging process since increased vascular intima media thickness, associated with luminal dilatation and a reduction in compliance, could be responsible for the decline in cardiovascular baroreflex sensitivity in older subjects $(30,31)$. Previous studies in young (32) and middle-aged subjects $(32,33)$ have demonstrated alterations in HRV indices due to postural changes. Other investigators have reported that these changes lose their statistical significance with advancing age $(34,35)$.

The cross-sectional design of this study is a limitation, since the characteristics of the autonomic control of HR in postmenopausal women prior to the use of estrogen therapy were not known. However, rigorous criteria of inclusion and exclusion in the study were established in order to control the factors that could influence autonomic control of the heart.

The results of the present study suggest that age plays an important role in autonomic cardiac modulation in female subjects. Estrogen therapy, in turn, seems to attenuate age-related modifications of the autonomic control of HR by promoting reduced sympathetic hyperactivity of the heart, thus contributing to the cardioprotector effect described in earlier studies $(3,4)$. Furthermore, our results indicate that physiological levels of estrogens are responsible for a higher vagal and lower sympathetic modulation of HR in our subjects. Studies are underway in our laboratory to evaluate the effects of long-term physical activity and hormonal therapy on the cardiovascular response at rest and during the exercise.

\section{References}

1. Kannel WB, Hjortland MC, McNamara PM, Gordon T. Menopause and risk of cardiovascular disease: the Framingham study. Ann Intern Med 1976; 85: 447-452.

2. Greendale GA, Lee NP, Arriola ER. The menopause. Lancet 1999; 353: $571-580$.

3. Stampfer MJ, Colditz GA, Willett WC, Manson JE, Rosner B, Speizer FE, et al. Postmenopausal estrogen therapy and cardiovascular disease. Ten-year follow-up from the nurses' health study. $N$ Engl $J$ Med 1991; 325: 756-762.

4. Grady D, Rubin SM, Petitti DB, Fox CS, Black D, Ettinger B, et al. Hormone therapy to prevent disease and prolong life in postmenopausal women. Ann Intern Med 1992; 117: 1016-1037.

5. The Writing Group for the PEPI Trial. Effects of estrogen or estrogen/progestin regimens on heart disease risk factors in postmenopausal women. The Postmenopausal Estrogen/Progestin Interventions (PEPI) Trial. JAMA 1995; 273: 199-208.

6. Mendelsohn ME. Protective effects of estrogen on the cardiovascular system. Am J Cardiol 2002; 89: 12E-17E.

7. Hulley S, Grady D, Bush T, Furberg C, Herrington D, Riggs B, et al. Randomized trial of estrogen plus progestin for secondary prevention of coronary heart disease in postmenopausal women. Heart and Estrogen/Progestin Replacement Study (HERS) Research
Group. JAMA 1998; 280: 605-613.

8. Rossouw JE, Anderson GL, Prentice RL, LaCroix AZ, Kooperberg $\mathrm{C}$, Stefanick ML, et al. Risks and benefits of estrogen plus progestin in healthy postmenopausal women: principal results from the Women's Health Initiative Randomized Controlled Trial. JAMA 2002; 288: 321-333.

9. Task Force of the European Society of Cardiology and the North American Society of Pacing and Electrophysiology. Heart rate variability: standards of measurement, physiological interpretation and clinical use. Circulation 1996; 93: 1043-1065.

10. Bigger JT Jr, Fleiss JL, Steinman RC, Rolnitzky LM, Kleiger RE, Rottman JN. Frequency domain measures of heart period variability and mortality after myocardial infarction. Circulation 1992; 85: 164171.

11. Acharya UR, Kannathal N, Sing OW, Ping LY, Chua T. Heart rate analysis in normal subjects of various age groups. Biomed Eng Online 2004; 3: 24.

12. Ribeiro TF, Azevedo GD, Crescencio JC, Maraes VR, Papa V, Catai $\mathrm{AM}$, et al. Heart rate variability under resting conditions in postmenopausal and young women. Braz J Med Biol Res 2001; 34: 871877.

13. Brockbank CL, Chatterjee F, Bruce SA, Woledge RC. Heart rate and 
its variability change after the menopause. Exp Physiol 2000; 85: 327-330.

14. Liu CC, Kuo TB, Yang CC. Effects of estrogen on gender-related autonomic differences in humans. Am J Physiol Heart Circ Physiol 2003; 285: H2188-H2193.

15. Mercuro G, Podda A, Pitzalis L, Zoncu S, Mascia M, Melis GB, et al. Evidence of a role of endogenous estrogen in the modulation of autonomic nervous system. Am J Cardiol 2000; 85: 787-789, A9.

16. Virtanen I, Polo O, Polo-Kantola P, Kuusela T, Ekholm E. The effect of estrogen replacement therapy on cardiac autonomic regulation. Maturitas 2000; 37: 45-51.

17. Yildirir A, Kabakci G, Yarali H, Aybar F, Akgul E, Bukulmez O, et al. Effects of hormone replacement therapy on heart rate variability in postmenopausal women. Ann Noninvasive Electrocardiol 2001; 6: 280-284.

18. Niskanen L, Laitinen T, Tuppurainen M, Saarikoski S, Kroger H, Alhava E, et al. Does postmenopausal hormone replacement therapy affect cardiac autonomic regulation in osteoporotic women? Menopause 2002; 9: 52-57.

19. Chobanian AV, Bakris GL, Black HR, Cushman WC, Green LA, Izzo $\mathrm{JL} \mathrm{Jr}$, et al. Seventh report of the Joint National Committee on Prevention, Detection, Evaluation, and Treatment of High Blood Pressure. Hypertension 2003; 42: 1206-1252.

20. Silva E, Catai AM, Trevelin LC, Guimarães JO, Silva LP Jr, Silva LM, et al. Design of a computerized system to evaluate the cardiac function during dynamic exercise. Phys Med Biol 1994; 39: 409 (Abstract).

21. Farag NH, Nelesen RA, Parry BL, Loredo JS, Dimsdale JE, Mills PJ. Autonomic and cardiovascular function in postmenopausal women: the effects of estrogen versus combination therapy. Am J Obstet Gynecol 2002; 186: 954-961.

22. Rosa Brito-Zurita O, Posadas-Romero C, Hermosillo AG, ZamoraGonzalez J, Hernandez-Ono A, Cardoso-Saldana G, et al. Estrogen effect on heart rate variability in hypertensive postmenopausal women. Maturitas 2003; 44: 39-48.

23. Virtanen I, Polo O, Saaresranta T, Kuusela T, Polo-Kantola P, Ekholm E. Medroxyprogesterone improves cardiac autonomic control in postmenopausal women with respiratory insufficiency. Respir Med 2004; 98: 126-133.

24. Christ M, Seyffart K, Tillmann HC, Wehling M. Hormone replace- ment in postmenopausal women: impact of progestogens on autonomic tone and blood pressure regulation. Menopause 2002; 9: 127-136.

25. Kuo TB, Lin T, Yang CC, Li CL, Chen CF, Chou P. Effect of aging on gender differences in neural control of heart rate. Am J Physiol 1999; 277: H2233-H2239.

26. Byrne EA, Fleg JL, Vaitkevicius PV, Wright J, Porges SW. Role of aerobic capacity and body mass index in the age-associated decline in heart rate variability. J Appl Physiol 1996; 81: 743-750.

27. Gokçe M, Karahan B, Yilmaz R, Orem C, Erdol C, Ozdemir S. Long term effects of hormone replacement therapy on heart rate variability, QT interval, QT dispersion and frequencies of arrhythmia. Int $J$ Cardiol 2005; 99: 373-379.

28. Anderson GL, Limacher M, Assaf AR, Bassford T, Beresford SA, Black $\mathrm{H}$, et al. Effects of conjugated equine estrogen in postmenopausal women with hysterectomy: the Women's Health Initiative Randomized Controlled Trial. JAMA 2004; 291: 1701-1712.

29. Lindqvist $A$. Noninvasive methods to study autonomic nervous control of circulation. Acta Physiol Scand Suppl 1990; 588: 1-107.

30. Monahan KD, Dinenno FA, Seals DR, Clevenger CM, DeSouza CA, Tanaka H. Age-associated changes in cardiovagal baroreflex sensitivity are related to central arterial compliance. Am J Physiol Heart Circ Physiol 2001; 281: H284-H289.

31. Lakatta EG, Levy D. Arterial and cardiac aging: major shareholders in cardiovascular disease enterprises: Part I: aging arteries: a "set up" for vascular disease. Circulation 2003; 107: 139-146.

32. Vuksanovic V, Gal V. Nonlinear and chaos characteristics of heart period time series: healthy aging and postural change. Auton Neurosci 2005; 121: 94-100.

33. Pikkujamsa SM, Makikallio TH, Airaksinen KE, Huikuri HV. Determinants and interindividual variation of R-R interval dynamics in healthy middle-aged subjects. Am J Physiol Heart Circ Physiol 2001; 280: H1400-H1406.

34. Perini R, Veicsteinas A. Heart rate variability and autonomic activity at rest and during exercise in various physiological conditions. Eur $J$ Appl Physiol 2003; 90: 317-325.

35. Sakabe DI, Catai AM, Neves VF, Oliveira L, Silva de Sá MF, Azevedo GD, et al. Análise da modulação autonômica do coração durante condições de repouso em homens de meia-idade e mulheres pós-menopausa. Rev Bras Fisioter 2004; 8: 89-95. 